\title{
Nitrogen in aramid-based activated carbon fibers by TPD, XPS and XANES
}

\author{
J.P. Boudou ${ }^{a, *}$ Ph. Parent ${ }^{b}$, F. Suarez-Garcia ${ }^{c}$, S. Villar-Rodil ${ }^{c}$, \\ A. Martinez-Alonso ${ }^{\mathrm{C}}$ J.M.D. Tascon ${ }^{\mathrm{c}}$ \\ a University Pierre et Marie Curie, CNRS, Case 120, 4 Place Jussieu, 75252 Paris cedex 05, France \\ $\mathrm{b}$ \\ Laboratoire de Chimie-Physique, Matie`re et Rayonnement, University Pierre et Marie Curie, CNRS (UMR 7614), \\ 11 rue Pierre et Marie Curie, 75231 Paris cedex 05, France \\ Instituto Nacional del Carbon, CSIC, Apartado 73, 33080 Oviedo, Spain
}

Abstract

Activated carbon fibers were prepared from Nomex@ [poly(m-phenylene isophthalamide)] by either $\mathrm{H}_{3} \mathrm{PO}_{4}$ activation, $\mathrm{H}_{3} \mathrm{PO}_{4}-\mathrm{CO}_{2}$ activation, or simply $\mathrm{CO}_{2}$ or steam activation. These treatments converted amide groups from the polymer precursor into complex and heterogeneously distributed nitrogen functionalities. TPD, XPS and XANES were used to study the effects of these treatments on the local bonding environment around nitrogen in the resulting carbons. These analytical techniques showed that nitrogen atoms are present in the 6-membered rings located at the edges of condensed polyaromatic systems as pyridine-like sp ${ }^{2}$ nitrogen (N1 or N2) or in the interior, where nitrogen replaces one carbon atom and is bonded to three carbon neighbors (N3). The occurrence of a species (N2) hypothetically related to a pyridinic cycle bearing oxygen substituents or intracyclic oxygen atoms could be correlated with the degree of oxidation of the carbon surface. Assuming that a relative N3 increase is indicative of aromatization and that the reverse, correlated with a N2 increase, is indicative of surface oxidative denitrogenation, the ratio between these nitrogen species revealed that aromatization and oxidative denitrogenation processes occur sequentially or simultaneously to different extents according to the type of carbon activation and to the burn-off degree. Physical activation involves thermal aromatization reactions during the carbonization stage and the subsequent isothermal activation one. In this second activation stage, co-occurring thermal oxidation reactions lead to a less intense denitrogenation during $\mathrm{CO}_{2}$ activation than during steam activation. $\mathrm{H}_{3} \mathrm{PO}_{4}$ activation induces the largest nitrogen retention in the final product in a double process of aromatization and "auto-activation"' producing a moderate oxidative attack of nitrogen. However, an increase of the $\mathrm{H}_{3} \mathrm{PO}_{4}$ ratio fostered the oxidation of the carbon surface and consequently enhanced nitrogen gasification during the subsequent activation.

Keywords: Activated carbon; Activation; Temperature programmed desorption; X-ray photoelectron spectroscopy; Functional groups

\section{Introduction}

In recent years, aramid fibers, more particularly Nomex@ [poly(m-phenylene isophthalamide)] (henceforth designated as Nomex), have been proposed as precursors for activated carbon materials with very homogeneous micropore size, usable as adsorbents, molecular sieves, cat-

* Corresponding author. Tel.: +33 6786316 62; fax: +33 1442741 64. Email address: boudou@ccr.jussieu.fr (J.P. Boudou). alysts or electrodes just to mention a few possible applications [1,2]. Since nitrogen from the precursor polymer is retained to a great extent in the derived carbonized and activated fibers, it is of interest to gain knowledge about the nitrogen chemistry in these materials. This type of work should also have some implications for the study of other nitrogen-containing types of carbon.

The present study investigates the structure and the thermal reactivity of nitrogen in Nomex-derived activated carbon fibers (NACFs) using temperature programmed 
desorption with detection of the nitrogen-containing gases by mass spectrometry (TPD-MS), X-ray photoelectron spectroscopy (XPS) and X-ray absorption near-edge structure (XANES). To date, TPD has often been used to study nitrogen in inorganic solids [3-6], but not so frequently in organic and carbon materials. Due to the expected interactions during thermal decomposition, nitrogen TPD can, at first sight, provide us only with indirect information on the distribution and reactivity of nitrogen groups present in the sample $[7,8]$. XPS is element-specific, but is particularly sensitive to surface effects and suffers from a lack of resolution: peak separations from different chemical forms of nitrogen are comparable to or less than peak widths. Nitrogen K-edge XANES brings additional details allowing a more precise interpretation of $\mathrm{N}$ functionalities present in the sample [9-12]. The positions of the lowest energy $n^{*}$ resonances can generally be used as a characteristic energy for the identification and quantification of aromatic nitrogen functionalities present in carbon materials. However, problems exist in resolving the resonances and in estimating the baseline, which make it difficult to identify and quantify the various species. XANES is a technique sensitive to all the forms of nitrogen that are present in the sample, which can provide us only with an average structure as a result. In this context, one of the major aims of this work is to find correlations between spectral features in these techniques for attempting a structural characterization of nitrogencontaining species present in the studied carbons. These results should help to understand details of the changes in nitrogen content and nitrogen functionality distribution as a function of the activation mode and of the burn-off degree.

\section{Experimental}

\subsection{Materials}

The precursor material was crystalline Nomex provided by DuPont Asturias. Various series of carbon adsorbents were prepared from either pure Nomex ( $\mathrm{N}$ series), or Nomex pre-impregnated with different amounts of $\mathrm{H}_{3} \mathrm{PO}_{4}$ (NP series). The impregnation process was carried out in a rotary evaporator, using each time $10 \mathrm{~g}$ Nomex and $200 \mathrm{ml}$ of solutions of phosphoric acid with different concentrations in order to vary the impregnation ratio. The temperature was increased progressively while stirring until complete evaporation of water; this process lasted for $6 \mathrm{~h}$. Then, the samples were dried overnight at $383 \mathrm{~K}$ in a vacuum furnace. The impregnation ratio $\left(\mathrm{X}_{\mathrm{p}}\right)$, calculated as the weight gain after impregnation relative to the initial mass of Nomex, [i.e. $\mathrm{X}_{\mathrm{p}}=\left(\mathrm{H}_{3} \mathrm{PO}_{4}\right.$ weight/ Nomex weight) $\mathrm{x}$ 100] amounted to 1,7 and 75 wt.\% depending on the phosphoric acid concentration. The resulting samples were named NP 1, NP7 and NP75, respectively (cf. Table 1).

Pyrolysis/physical activation treatments with $\mathrm{CO}_{2}$ of Nomex, fresh or impregnated with $X_{p}=1$ or $7 \mathrm{wt} . \%$
$\mathrm{H}_{3} \mathrm{PO}_{4}$, was carried out in a vertical reactor made of quartz, using 4-5 g of sample, a flow of $\operatorname{Ar}$ (99.999\% pure) of $50 \mathrm{~cm}^{3} \mathrm{~min}^{-1}$ and a heating rate of $10 \mathrm{~K} \mathrm{~min}^{-1}$ until $1123 \mathrm{~K}$; once this temperature was attained, the samples were either rapidly cooled down to room temperature ( $\mathrm{N}$ sample, only pyrolyzed), or to $1073 \mathrm{~K}$. In the latter case, the gas flow was then changed to $50 \mathrm{~cm}^{3} \mathrm{~min}^{-1} \mathrm{CO}_{2}$ (99.98\% pure), and it was kept for different time intervals to attain different burn-offs. Pyrolysis/physical activation treatments with steam were conducted in the same reactor. In this case, batches of about $10 \mathrm{~g}$ of Nomex were pyrolyzed in $\mathrm{Ar}$ (99.999 vol.\% pure, flow rate of $\left.50 \mathrm{~cm}^{3} \mathrm{~min}-1\right)$ up to $1073 \mathrm{~K}$ (heating rate, $10 \mathrm{~K} \mathrm{~min}^{-1}$ ) and then cooled down to $1053 \mathrm{~K}$ and activated with a steam/argon mixture $\left(720 / 50 \mathrm{~cm}^{3} \mathrm{~min}^{-1}\right)$ for various periods of time to attain different burn-offs.

Chemical activations were carried out in a U-shaped reactor made from quartz, using $3 \mathrm{~g}$ of impregnated Nomex (75 wt.\% $\mathrm{H}_{3} \mathrm{PO}_{4}$ ), an Ar flow of $50 \mathrm{~cm}^{3} \mathrm{~min}-1$ and a heating rate of $10 \mathrm{~K} \mathrm{~min}^{-1}$ until the final temperature ( 873 or $1073 \mathrm{~K}$ ). Once this temperature was attained, the sample was rapidly cooled down to room temperature. Then, the resulting materials were washed with water in a Soxhlet extractor to eliminate the excess of phosphoric acid and/or its decomposition products until the conductivity in the washing liquids was $<3 \mathrm{gS} \mathrm{cm}^{-1}$. The yield and the burnoff of samples prepared from pre-impregnated Nomex were calculated from the final mass (after washing and drying) relative to the initial mass of Nomex before impregnation.

The studied NACFs and their preparation conditions are listed in Table 1, whereas Table 2 gives their elemental analysis on a dry basis. The elemental analyses were carried out in a microanalysis apparatus, LECO CHNS-932, provided with an oxygen analyzer, LECO VTF-900. The mass loss of selected NACFs between room temperature and $1273 \mathrm{~K}$ was studied in a Stanton-Redcroft STA-1500

Table 1

List of studied samples

\begin{tabular}{|c|c|}
\hline \multirow{2}{*}{$\begin{array}{l}\text { Sample code } \\
\mathrm{N}\end{array}$} & Sample description \\
\hline & Nomex carbonized up to $1123 \mathrm{~K}$ \\
\hline NC4 & $\mathrm{N}$ activated with $\mathrm{CO}_{2}$ at $1073 \mathrm{~K}$ with $4 \%$ bum-off \\
\hline NC41 & $\mathrm{N}$ activated with $\mathrm{CO}_{2}$ at $1073 \mathrm{~K}$ with $41 \%$ bum-off \\
\hline NH10 & $\mathrm{N}$ activated with steam at $1053 \mathrm{~K}$ with $10 \%$ bum-off \\
\hline NH42 & $\mathrm{N}$ activated with steam at $1053 \mathrm{~K}$ with $42 \%$ bum-off \\
\hline NP1 & $\begin{array}{l}\text { Nomex impregnated with } 1 \% \mathrm{H}_{3} \mathrm{PO}_{4} \text { and carbonized } \\
\text { up to } 1123 \mathrm{~K}\end{array}$ \\
\hline NP1C16 & NP1 activated with $\mathrm{CO}_{2}$ at $1073 \mathrm{~K}$ with $16 \%$ bum-off \\
\hline NP1C26 & NP1 activated with $\mathrm{CO}_{2}$ at $1073 \mathrm{~K}$ with $26 \%$ bum-off \\
\hline NP7 & $\begin{array}{l}\text { Nomex impregnated with } 7 \% \mathrm{H}_{3} \mathrm{PO}_{4} \text { and carbonized } \\
\text { up to } 1123 \mathrm{~K}\end{array}$ \\
\hline NP7C14 & NP7 activated with $\mathrm{CO}_{2}$ at $1073 \mathrm{~K}$ with $14 \%$ bum-off \\
\hline NP7C32 & NP7 activated with $\mathrm{CO}_{2}$ at $1073 \mathrm{~K}$ with $32 \%$ bum-off \\
\hline NP75-873 & $\begin{array}{l}\text { Nomex impregnated with } 75 \% \mathrm{H}_{3} \mathrm{PO}_{4} \text { and carbonized } \\
\text { up to } 873 \mathrm{~K}\end{array}$ \\
\hline NP75-1073 & $\begin{array}{l}\text { Nomex impregnated with } 75 \% \mathrm{H}_{3} \mathrm{PO}_{4} \text { and carbonized } \\
\text { up to } 1073 \mathrm{~K}\end{array}$ \\
\hline
\end{tabular}


Table 2

Elemental analysis (wt.\%, dry basis)

\begin{tabular}{lcccr}
\hline Sample & $\mathrm{C}$ & $\mathrm{H}$ & $\mathrm{N}$ & $\mathrm{O}$ \\
\hline $\mathrm{N}$ & 83.5 & 1.47 & 6.29 & 8.4 \\
NC4 & 82.8 & 1.20 & 5.23 & 5.2 \\
NC41 & 82.4 & 1.17 & 4.50 & 3.7 \\
NH10 & 79.3 & 2.35 & 4.51 & 12.1 \\
NH42 & 81.5 & 2.11 & 4.63 & 10.0 \\
NP1 & 83.4 & 0.56 & 7.13 & 9.6 \\
NP1C16 & 85.4 & 0.64 & 5.53 & 4.8 \\
NP1C26 & 87.8 & 0.49 & 5.14 & 4.4 \\
NP7 & 80.7 & 0.58 & 6.65 & 12.8 \\
NP7C14 & 79.2 & 0.82 & 5.41 & 8.5 \\
NP7C32 & 76.3 & 1.30 & 4.18 & 12.5 \\
NP75-873a & 70.4 & 2.32 & 8.02 & 12.4 \\
NP75-1073a & 67.8 & 1.41 & 6.12 & 16.7 \\
\hline
\end{tabular}

$\mathrm{a}_{\%} \mathrm{P}=1.8$ (NP75-873) or 2.8 wt.\% (NP75-1073).

thermobalance, using $15 \mathrm{mg}$ sample, a heating rate of 10 or $30 \mathrm{~K} \mathrm{~min}^{-1}$ and an Ar flow of $50 \mathrm{~cm}^{3}$ min-1.

The porous texture of NACFs was analyzed from physical adsorption isotherms of $\mathrm{N}_{2}$ at $77 \mathrm{~K}$, measured in an ASAP 2010 volumetric apparatus (Micromeritics) and $\mathrm{CO}_{2}$ at $273 \mathrm{~K}$, measured in a NOVA 1200 volumetric apparatus (Quantachrome). In either case, the samples were previously degassed overnight at $523 \mathrm{~K}$. Porous texture parameters obtained from the $\mathrm{N}_{2}$ and $\mathrm{CO}_{2}$ isotherms are presented in Table 3 . The $\mathrm{N}_{2}$ isotherms were analyzed by means of the BET method (using data in the relative pressure range of $0.01-0.1$ ) to calculate the specific surface area $\left(\mathrm{S}_{\mathrm{BET}}\right)$, and the DubininRadushkevich (DR) equation to calculate the micropore volume $\left[\mathrm{V}_{{ }_{\mathrm{p}}}\left(\mathrm{N}_{2}\right)\right]$; the total pore volume $\left(\mathrm{V}_{\mathrm{Pt}}\right)$ was calculated from nitrogen uptake at

Table 3

\begin{tabular}{|c|c|c|c|c|c|c|}
\hline Sample & $\begin{array}{l}\mathrm{V}_{\mathrm{lp}_{\mathrm{p}}} \\
\left(\mathrm{CO}_{2}\right)\end{array}$ & $\begin{array}{l}\mathrm{V}_{\mathrm{lp}_{\mathrm{p}}}\left(\mathrm{N}_{2}\right), \\
\mathrm{cm}^{3} \mathrm{~g}^{-1}\end{array}$ & $\begin{array}{l}V_{p t} \\
\left(N_{2}\right)\end{array}$ & $\begin{array}{l}\mathrm{S}_{\text {B E T }} \\
\mathrm{m}_{2} \mathrm{~g}-1\end{array}$ & $\begin{array}{l}\text { Burn-off, } \\
\text { wt.\% a.r. }\end{array}$ & $\begin{array}{l}\text { Yield } \\
\text { wt.\% a.r. }\end{array}$ \\
\hline \multicolumn{7}{|l|}{ Initial char } \\
\hline $\mathrm{N}$ & 0.18 & 0 & 0 & & 0 & 52.8 \\
\hline \multicolumn{7}{|c|}{$\mathrm{CO}_{2}$ activation } \\
\hline NC4 & 0.22 & 0.22 & 0.22 & 556 & 4 & 50.8 \\
\hline NC41 & 0.41 & 0.48 & 0.50 & 1241 & 41 & 31.3 \\
\hline \multicolumn{7}{|c|}{ Steam activation } \\
\hline NH10 & 0.22 & 0.23 & 0.23 & 560 & 10 & 47.5 \\
\hline NH42 & 0.29 & 0.56 & 0.56 & 1329 & 40 & 31.5 \\
\hline \multicolumn{7}{|c|}{$\mathrm{H}_{3} \mathrm{PO}_{4}(1 \%) / \mathrm{CO}_{2}$ activation } \\
\hline NP1 & 0.20 & 0 & 0 & 1 & 0 & 57.1 \\
\hline NP1C16 & 0.27 & 0.32 & 0.32 & 823 & 16 & 48.2 \\
\hline NP1C26 & 0.41 & 0.41 & 0.42 & 1048 & 26 & 42.3 \\
\hline \multicolumn{7}{|c|}{$\mathrm{H}_{3} \mathrm{PO}_{4}(7 \%) / \mathrm{CO}_{2}$ activation } \\
\hline NP7 & 0.24 & 0 & 0 & 1 & 0 & 64.1 \\
\hline NP7C14 & 0.26 & 0.27 & 0.28 & 707 & 14 & 55.1 \\
\hline NP7C32 & 0.35 & 0.40 & 0.41 & 1030 & 32 & 43.8 \\
\hline \multicolumn{7}{|c|}{$\mathrm{H}_{3} \mathrm{PO}_{4}(7 \quad \%)$ activation } \\
\hline NP75-873 & 0.35 & 0.38 & 0.39 & 951 & & 68.0 \\
\hline NP75-1073 & 0.38 & 0.38 & 0.39 & 987 & & 57.0 \\
\hline
\end{tabular}

a.r.: As-received.
0.975 relative pressure, assuming $\mathrm{N}_{2}$ to be in the liquid state (Gurvitsch rule). The $\mathrm{CO}_{2}$ isotherms were analyzed by means of the DR equation to calculate the corresponding micropore volume $\left[{ }_{1 \mathrm{p}}^{\mathrm{V}}\left(\mathrm{CO}_{2}\right)\right]$. Table 3 also includes data for the burn-off (mass loss during activation, relative to mass of char) and yield (mass loss during activation, relative to mass of Nomex precursor).

\subsection{TPD}

For TPD, the sample (ca. $5 \mathrm{mg}$ ) was placed in a $\mathrm{He}+1 \%$ Ne flow of $10 \mathrm{~cm}^{3} \mathrm{~min}^{-1}$ under atmospheric pressure and heated at $30 \mathrm{~K} \mathrm{~min}^{-1}$. Evolved gases were continuously detected with a quadrupole mass spectrometer. $\mathrm{N}_{2}$ was detected after selective oxidation of $\mathrm{CO}$ as $\mathrm{CO}_{2}$ on $\mathrm{MnO}_{2}$ at $393 \mathrm{~K}$. External calibration was done using mixtures of the gas to calibrate in pure helium with $1 \%$ neon. The signal amplitude of a selected mass was related to the $\mathrm{m} / \mathrm{z} 20$ amplitude of neon. In this work, physisorbed water occurs as a large peak, probably as a result of steam interactions with the inner wall of the transfer line between the oven and the detector. Calibration of the integrated signal of physisorbed water was used to assess the sample moisture and hence to express the TPD gas yield with respect to the dry matter.

\subsection{XPS}

XPS signals were recorded using a VG Scientific ESCALAB 250 system (based at ITODYS, Universite' Paris 7, Paris, France) equipped with a micro-focused, monochromated Al Ka X-ray source (1486.6 eV, 650 „m spot size, $200 \mathrm{~W}$ ) and a magnetic immersion lens which permits to enhance the sensitivity by ca. one order of magnitude. The spectra were acquired with pass energies of 150 and $20 \mathrm{eV}$ for the survey and the high resolution spectra, respectively. No N1s binding energy correction was done, with respect to the C1s one, because the sample, mounted onto a conducting double-sided adhesive tape, did not exhibit any charging effects. The Avantage software, version 1.85, was used for digital acquisition and data processing. The compositions (in at.\%) were determined by considering the integrated peak areas of $\mathrm{C} 1 \mathrm{~s}, \mathrm{~N} 1 \mathrm{~s}, \mathrm{O} 1 \mathrm{~s}$ and $\mathrm{P} 2 \mathrm{p}$ from the survey spectra and the respective sensitivity factors.

\subsection{XANES}

XANES measurements were performed at the Laboratoire pour l'Utilisation du Rayonnement Electromagne'tique (LURE, Orsay, France) on the VUV Super-Aco storage ring. They were carried out at a resolution of $-0.2 \mathrm{eV}$ at the nitrogen $\mathrm{K}$ edge. The samples were ground to about 20 „m particle size, dispersed in acetone, and applied drop-wise to high-purity tungsten plates, and the solvent was allowed to evaporate. All measurements were made at room temperature under ultra high vacuum. 
Calibration of the photon energy scale at the N1s edge was made to match the $\mathrm{N} 1 \mathrm{~s}-\mathrm{n} *$ of $\mathrm{C}=\mathrm{N}$ in polyacrylonitrile (PAN, Aldrich) at $401.4 \mathrm{eV}$. The N K-edge XANES spectra of $1 s+n^{*}$ transitions were deconvoluted with GaussianLorentzian curves after subtraction of an error function step to the experimental XANES spectra.

\section{Results and discussion}

\subsection{TPD}

Temperature-programmed desorption profiles recorded at $30 \mathrm{~K} \mathrm{~min}^{-1}$ from 300 to $1750 \mathrm{~K}$ are presented in Fig. 1. As shown in Fig. 2 and Table 4, total TPD gas yields are of the same order of magnitude as the total mass loss recorded by thermogravimetry at $30 \mathrm{~K} \mathrm{~min}^{-1}$. TG curve tailing at temperatures above the peak maximum at $1075-1125 \mathrm{~K}$ (Fig. 2) could be attributed, in the case of samples NP75-873 and NP75-1073 (which underwent the largest mass losses), to vaporization of $\mathrm{P}_{2} \mathrm{O}_{5}$ (coming from decomposition of unreacted phosphoric acid and/or products from its reaction with Nomex); this process takes place above ca. $1000 \mathrm{~K}$ at lower heating rate [13]. For the rest of samples, mass losses above $1173 \mathrm{~K}$ (maximum temperature to which some of the samples were exposed during their preparation) are rather attributable to loss of very stable functional groups and/or other constituents. At the temperature of maximum mass loss rate, around $1100 \mathrm{~K}$, the main gases released are carbon monoxide and water. Physisorbed water and carbon dioxide coming from postcooling exposure to the atmosphere evolve earlier, and molecular hydrogen together with several nitrogen containing gases occurs later. The thermal desorbed water peak was computed by subtraction of the whole water signal with the physisorbed water tailing curve. This background curve was obtained by extra- and interpolation of the physisorbed water tailing curve appearing before and after the thermal desorbed water peak that results from removal of chemisorbed oxygen. The background corrected water peak (desorbed water) occurs between ca. 750 and

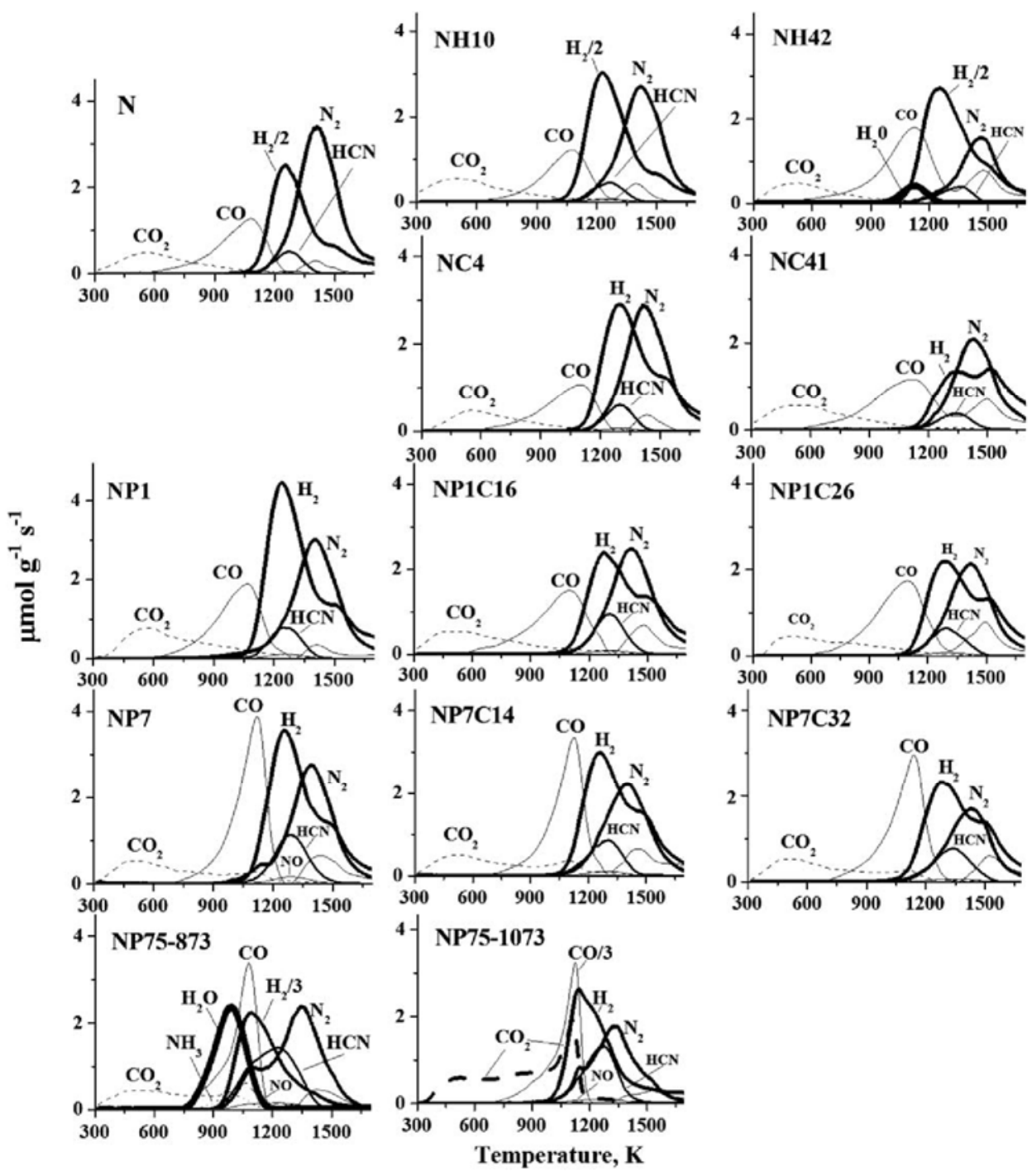

Fig. 1. TPD profiles of the Nomex char (N) and Nomex-based activated carbon fibers. 


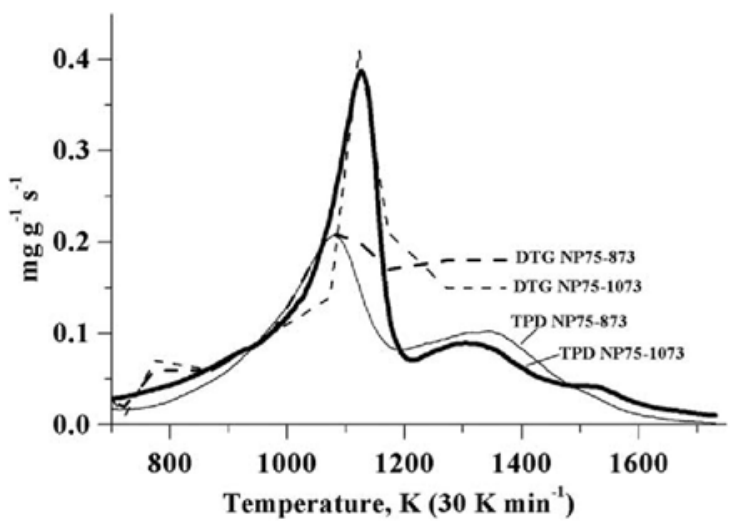

Fig. 2. Comparison between total evolution rates measured by thermogravimetry and by TPD.

$1200 \mathrm{~K}$ with a symmetrical shape along an apparent pseudosecond-order kinetics. After correction, only $\mathrm{NH} 42$ and NP75-873 displayed some desorbed water, which occurs much above the main $\mathrm{CO}_{2}$ peak, so that it cannot result from $\mathrm{H}$-bonded $\mathrm{H}_{2} \mathrm{O}$ associated with acidic oxygen complexes, but from the thermal condensation of hydroxyl groups initially present, or secondarily formed, in the solid sample [14-17]. Molecular hydrogen evolved from all the studied samples in two steps above $900 \mathrm{~K}$, as a result of condensation between polyaromatic systems forming hydrogen radicals. The materials obtained by steam activation and by $\mathrm{H}_{3} \mathrm{PO}_{4}$ activation are the most hydrogenated ones (Table 2), and accordingly they liberate more hydrogen (Table 3) and this release occurs at lower temperatures, than for the rest of samples. In contrast, samples obtained by $\mathrm{CO}_{2}$ activation release much less hydrogen and this occurs at a higher temperature $(>1450 \mathrm{~K})$.

The quantification of the thermal desorption of $\mathrm{CO}_{2}$ or $\mathrm{CO}$ in the low temperature range is hindered by the simultaneous desorption of simply physisorbed species and the removal of gaseous compounds formed by the breakdown of fragile surface functional groups [18]. In the present work, the first peaks and shoulders at the beginning of programmed heating that are due to physisorbed $\mathrm{CO}_{2}$ or $\mathrm{CO}$, were deleted from the whole profile (which was fitted by summation of a series of equations of first-order kinetics). The assignment of $\mathrm{CO}$ - and $\mathrm{CO}_{2}$-yielding groups was made on the basis on the current literature [19-25]. The proportion of $\mathrm{CO}_{2}$ - and $\mathrm{CO}$-generating complexes varies with the sample treatment: the samples activated with $\mathrm{H}_{3} \mathrm{PO}_{4}$ are the most acidic ones (highest $\mathrm{CO}_{2}$ evolution) and display the highest fraction of high-temperature $\mathrm{CO}_{2}$-generating complexes (lactone/anhydride type and/or adjacent acidic oxygen complexes formed at dangling carbon sites during post-activation ageing), whereas the samples activated physically display the highest fraction of high temperature CO-evolving complexes (chromene type). The lack of correlation between $\mathrm{CO}$ and $\mathrm{CO}_{2}$ yields and the porous texture (Table 3 ) suggests that $\mathrm{CO}$ - and $\mathrm{CO}_{2}$-evolving complexes would not have been formed over the entire surface area of the chars during the activation process [25]. Some of these complexes would have been formed after cooling by low temperature oxidation.

As shown in Fig. 1, the activation methods of the Nomex fibers produce several types of $\mathrm{N}$-containing gas

Table 4

TPD and TG yields

\begin{tabular}{|c|c|c|c|c|c|c|c|c|c|c|c|}
\hline \multirow[t]{2}{*}{$\overline{\text { Sample }}$} & \multicolumn{6}{|c|}{ TPD yields, mmol gg ga } & \multicolumn{5}{|c|}{ Total loss, wt.\% } \\
\hline & $\mathrm{H}_{2} \mathrm{O}$ & $\mathrm{CO}_{2}$ & $\mathrm{CO}$ & $\mathrm{H}_{2}$ & $\mathrm{~N}_{2}$ & $\mathrm{HCN}$ & NO & $\mathrm{NH}_{3}$ & TPD30K & TG30K & TG10K \\
\hline \multicolumn{12}{|l|}{ Initial char } \\
\hline $\mathrm{N}$ & 0.00 & 0.50 & 0.80 & 2.60 & 1.70 & 0.20 & 0.00 & 0.00 & 19.1 & 14.9 & 22.3 \\
\hline \multicolumn{12}{|c|}{$\mathrm{CO}_{2}$ activation } \\
\hline NC4 & 0.00 & 0.50 & 0.80 & 2.00 & 1.70 & 0.20 & 0.00 & 0.00 & 16.8 & 14.6 & 25.6 \\
\hline NC41 & 0.00 & 0.60 & 1.30 & 1.30 & 1.20 & 0.20 & 0.00 & 0.00 & 28.2 & 33.8 & 37.8 \\
\hline \multicolumn{12}{|c|}{ Steam activation } \\
\hline NH10 & 0.00 & 0.50 & 0.80 & 3.20 & 1.40 & 0.20 & 0.00 & 0.00 & 15.4 & 12.8 & 25.0 \\
\hline NH42 & 0.10 & 0.50 & 1.60 & 3.60 & 0.90 & 0.20 & 0.00 & 0.00 & 18.7 & 11.8 & 26.1 \\
\hline \multicolumn{12}{|c|}{$\mathrm{H}_{3} \mathrm{PO}_{4}(1 \%) / \mathrm{CO}_{2}$ activation } \\
\hline NP1 & 0.00 & 0.80 & 1.30 & 2.90 & 1.90 & 0.40 & 0.10 & 0.00 & 18.3 & 20.7 & 25.5 \\
\hline NP1C16 & 0.00 & 0.50 & 1.00 & 1.70 & 1.40 & 0.40 & 0.10 & 0.00 & 27.4 & 28.2 & 47.8 \\
\hline NP1C26 & 0.00 & 0.50 & 1.50 & 1.70 & 1.20 & 0.30 & 0.10 & 0.00 & 33.4 & 34.3 & 49.5 \\
\hline \multicolumn{12}{|c|}{$\mathrm{H}_{3} \mathrm{PO}_{4}(7 \%) / \mathrm{CO}_{2}$ activation } \\
\hline NP7 & 0.00 & 0.60 & 1.70 & 2.40 & 1.70 & 0.50 & 0.10 & 0.00 & 23.9 & 23.5 & 33.9 \\
\hline NP7C14 & 0.00 & 0.70 & 1.70 & 2.10 & 1.40 & 0.40 & 0.10 & 0.00 & 25.0 & 27.5 & 37.7 \\
\hline NP7C32 & 0.00 & 0.60 & 1.60 & 1.90 & 1.00 & 0.40 & 0.10 & 0.00 & 28.2 & 29.0 & 38.4 \\
\hline \multicolumn{12}{|c|}{$\mathrm{H}_{3} \mathrm{PO}_{4}(75 \%)$ activation } \\
\hline NP75-873 & 1.20 & 0.90 & 1.60 & 4.70 & 1.90 & 1.10 & 0.20 & 0.20 & 34.0 & 35.0 & 46.1 \\
\hline NP75-1073 & 0.00 & 1.40 & 3.70 & 1.70 & 1.30 & 0.70 & 0.10 & 0.00 & 34.6 & 34.9 & 46.1 \\
\hline
\end{tabular}

a From 300 to $1723 \mathrm{~K}$ at $30 \mathrm{~K}$ minn $_{1}$.

${ }^{\mathrm{b}}$ From 300 to $1373 \mathrm{~K}$ at 10 or $30 \mathrm{~K}$ minn. 
species distribution, which can be correlated with the $\mathrm{H}$ and O-containing gas species distributions. The largest part of nitrogen evolves as molecular nitrogen in two steps: the first one below $1150 \mathrm{~K}$ (only in samples NP7, NP75-873 and NP75-1073), and the second one - the most important above this temperature - centered between the two $\mathrm{H}_{2}$ peaks. HCN evolves in one peak in the same temperature range as $\mathrm{H}_{2}$. In the most oxidized samples (those activated by $\left.\mathrm{H}_{3} \mathrm{PO}_{4}\right), \mathrm{HCN}$ co-evolves with $\mathrm{NO}$ and its peak is almost as high as the $\mathrm{N}_{2}$ one. The sample NP75-873, prepared at relatively low temperature, releases a small amount of $\mathrm{NH}_{3}$, which co-evolves with the desorbed water just before the first $\mathrm{H}_{2}$ peak. Positive correlations (not shown) of $\mathrm{HCN} / \mathrm{N}_{2}$ ratio with the carbonization/activation yield (Table 3 ) or with the atomic $\mathrm{O} / \mathrm{C}$ ratio (which can be computed from Table 2) suggest that oxygen groups at the edge of condensed polyaromatic clusters would make the $\mathrm{N}$ polyaromatic skeleton more fragile and hence prone to earlier generation of $\mathrm{N}$-containing radical species, which in the absence of a sufficient amount of hydrogen radicals are involved in secondary gas phase reactions leading first to hydrogen derivatives ( $\mathrm{HCN}, \mathrm{NH}_{3}$ ) and then giving $\mathrm{N}_{2}$ in the absence of a sufficient amount of hydrogen radicals involved in the secondary gas phase reactions. A proof of that would be that hydrogen addition preserves the primary nitrogen fragments resulting from solid phase reactions (decomposition of functional groups in the carbon

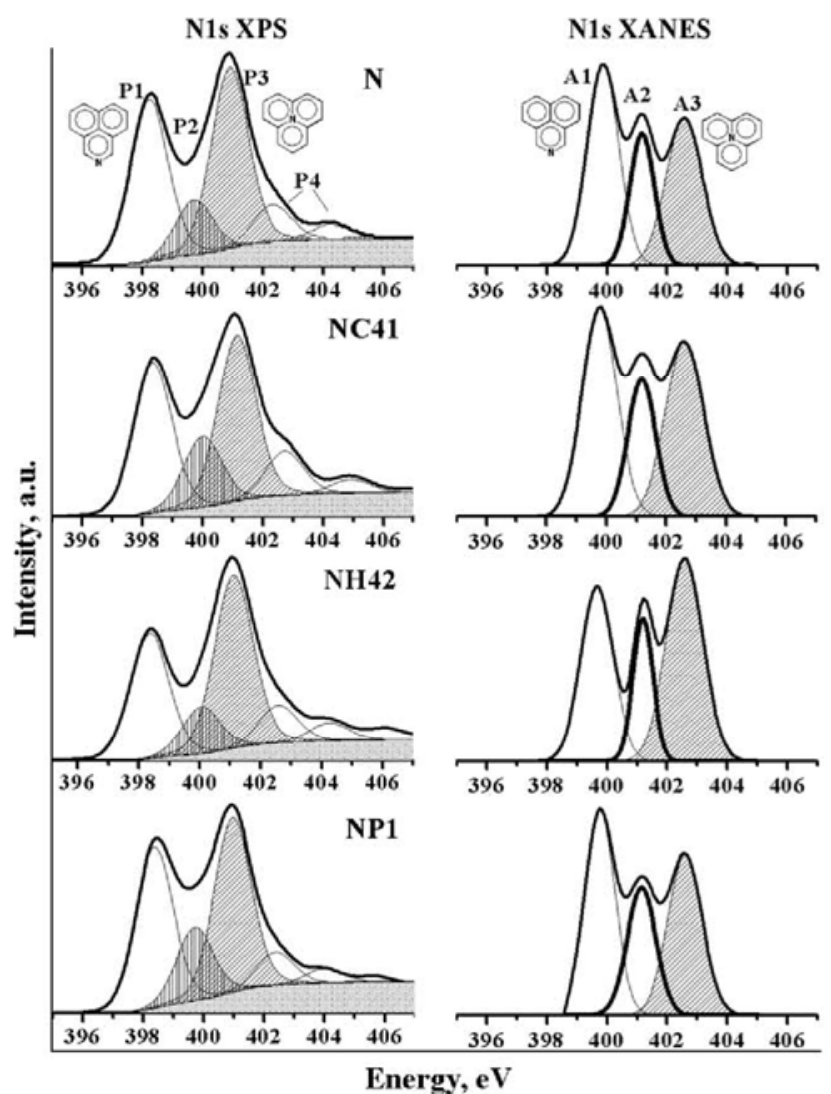

structure and interfacial reactions): the largest part of nitrogen evolves in the low temperature range, and consequently $\mathrm{NH}_{3}$ and $\mathrm{HCN}$ evolution increases.

\subsection{XPS and XANES}

XPS survey spectra, together with N1s core level photoelectron spectra, the $\mathrm{N}$ K-egde XANES spectra and nitrogen TPD-MS profiles for selected NACFs, are compared in Fig. 3. In agreement with previous works $[9,26]$, the XPS N1s spectra show, depending on the sample, three to five components: two dominant peaks plus some smaller contributions. In the $\pi *$ region of the XANES spectra, three peaks can be distinguished. To obtain acceptable curve fittings, the XPS spectra were decomposed into five peaks (labeled P1-P5) and the XANES spectra into three (labeled A1-A3) (Table 5). Note that the $\pi^{*}$ resonances should fall at nearly the same energy than the photoemission peaks [10].

The components P1, P3, A1 and A3 appear as discernible peaks in the N1s envelop and can be structurally assigned as follows. P1 and A1 can be related to pyridinic nitrogen in non-functionalized heterocycles (i.e., where $\mathrm{N}$ atoms contribute to the $\mathrm{n}$ system with one n-electron bond to two $\mathrm{sp}^{2}$ carbons not linked to another heteroatom), and to a lesser extent to arylnitriles, which may be over-evaluated because the nitrile bond predominantlv has a $n$ svstem
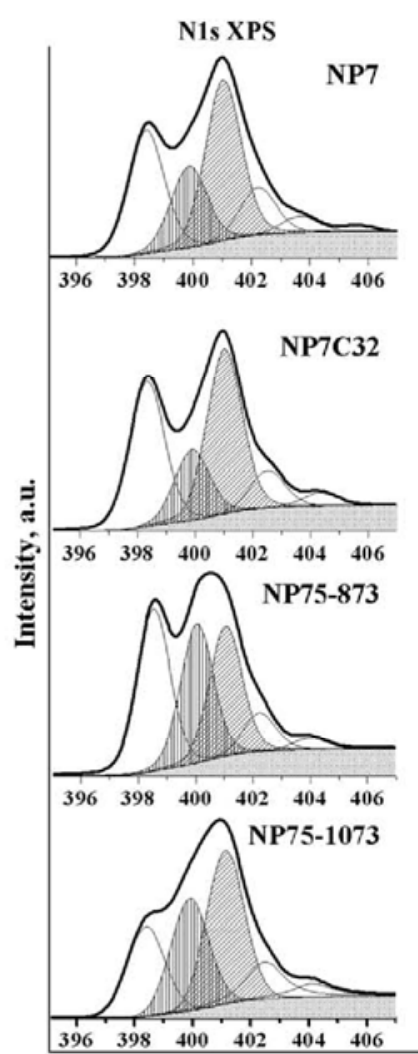

Energy, eV
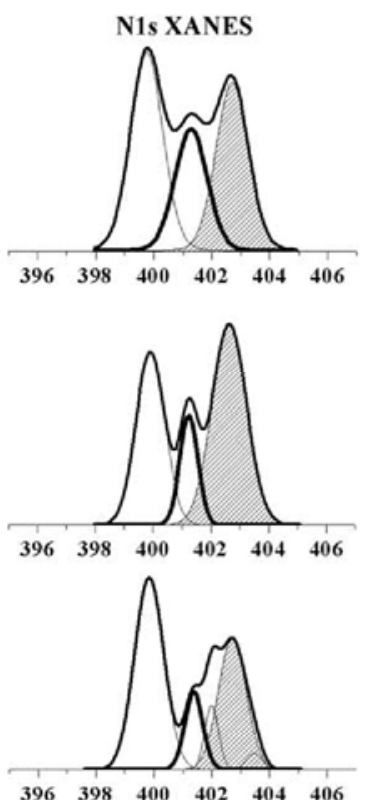

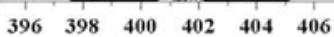

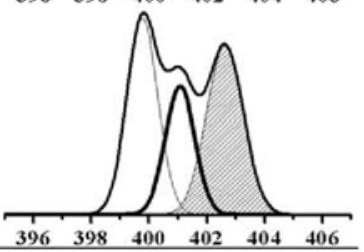

Fig. 3. N1s XPS, n region of the N K-egde XANES spectra. 
Table 5

N1s XPS (P) and XANES (A) data

\begin{tabular}{lrllllllllll}
\hline Sample & \multicolumn{1}{c}{$\begin{array}{l}\text { XPS atomic } \\
\text { ratios x }\end{array}$ 100 } & \multicolumn{8}{c}{$\begin{array}{l}\text { Relative area of N1s components, } \\
\text { \% of total area }\end{array}$} \\
\cline { 2 - 11 } & O/C & N/C P/C P1 & \multicolumn{1}{c}{ P2 } & P3 & P4 & A1 & A2 & A3 \\
\hline N & 3.19 & 5.09 & - & 36.1 & 11.5 & 40.5 & 11.8 & 42.0 & 21.0 & 36.0 \\
NC41 & 4.54 & 3.42 & - & 33.6 & 15.8 & 37.1 & 12.8 & 40.8 & 21.5 & 37.7 \\
NH42 & 3.69 & 3.08 & - & 30.1 & 11.2 & 41.6 & 13.3 & 35.5 & 17.9 & 46.6 \\
NP1 & 5.47 & 5.34 & - & 37.0 & 16.9 & 40.2 & 11.0 & 40.2 & 24.0 & 35.8 \\
NP1C26 & 5.19 & 4.61 & 0.16 & 33.9 & 14.4 & 41.7 & 10.0 & 34.5 & 24.0 & 41.5 \\
NP7 & 6.38 & 4.44 & 0.56 & 29.6 & 19.6 & 38.6 & 15.2 & 40.4 & 24.9 & 34.4 \\
NP7C32 & 6.66 & 3.62 & 0.60 & 34.0 & 16.6 & 38.8 & 11.7 & 35.2 & 22.4 & 42.3 \\
NP75-873 & 9.66 & 5.56 & 1.84 & 33.6 & 28.8 & 27.0 & 10.6 & 47.6 & 19.6 & 30.6 \\
NP75-1073 & 12.36 & 4.77 & 2.75 & 21.1 & 26.2 & 35.8 & 15.4 & 37.9 & 23.4 & 38.7 \\
\hline
\end{tabular}

with large oscillator strength [12]. According to previous findings [8], P3 and A3 can be assigned to substitutional nitrogen in condensed polyaromatic systems where nitrogen substitutes carbon [10-12,27-29]. They can be related to aromatization and microstructure ordering $[8,30]$. When carbon surface bears hydroxyl groups, which generate water by thermal decomposition, as seen by water TPD for NH42 and NP75-873 (Fig. 1), the XPS peak P3 could also be assigned to quaternary nitrogen resulting from weak pyridine protonation by adjacent or nearby located hydroxyl groups forming hydrogen bridge with the pyridinic nitrogen [31-34].

The hidden P2 and A2 components show no clear relationship with each other (Fig. 4a) since P2 is assigned to some nitrogen species which would not have any $\mathrm{n}^{*}$ resonance in arylnitrile or pyridine structures as found for A2
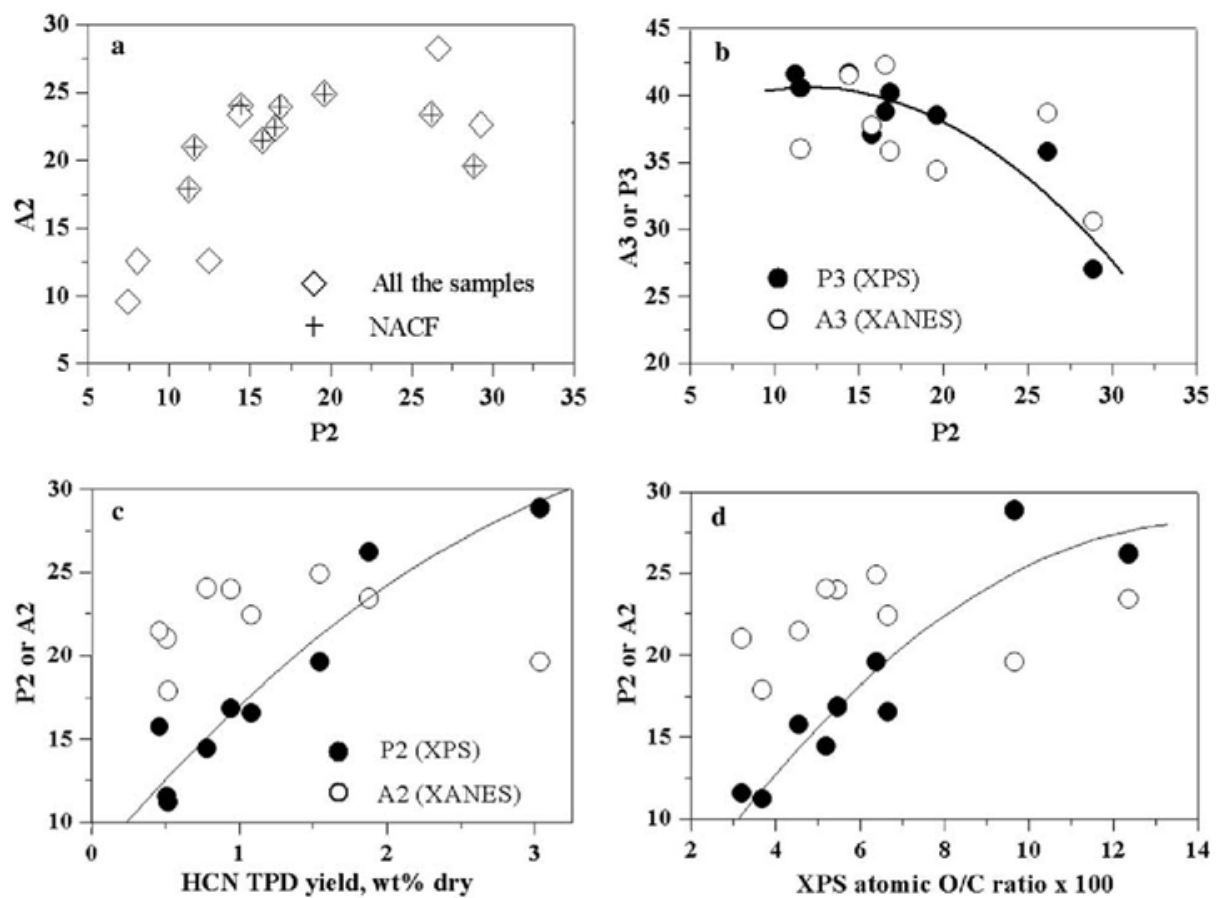

Fig. 4. Correlations between N1s XPS, XANES XPS hidden peak relative area (ra), atomic O/C ratio and HCN TPD yield: (a) XANES A2 ra vs. XPS P2 ra, where NACF data are plotted together with samples from [8,42]; (b) XANES A3 or XPS P3 ra vs. XPS P2 ra; (c) XPS P2 or XANES A2 ra vs. HCN TPD yield; (d) XPS P2 or XANES A2 vs. XPS atomic O/C ratio. 
for A2/P2 components such as amide, pyridine, nitrile or nitroxy groups (these groups can thermally generate $\mathrm{N}_{2}$, $\mathrm{NO}$, ammonia and/or HCN at relatively low temperature instead of only $\mathrm{N}_{2}$ at high temperature). Therefore, on the basis of reactional behaviour and correlations, we will assume that A2/P2 in activated carbons would be related to pyridinic cycle bearing oxygen substituents or intracyclic oxygen atoms making the cycle more prone to be open by thermal cracking during TPD and to release both HCN and $\mathrm{N}_{2}$ at lower temperature rather than pure $\mathrm{N}_{2}$ formed as a result of surface or gas phase radical recombination due to hydrogen starvation at higher temperature. The negative correlation between P3 or A3 and the oxidation degree (indirectly measured by $\mathrm{P} 2$ in NACF in Fig. 4b, itself well correlated with HCN TPD yields in Fig. 4c, as well as with atomic O/C ratio in Fig. 4d), suggests that, in agreement with previous works on nitrogen transformation during gasification or during wet oxidation [44,45], condensed polyaromatic systems bearing substitutional nitrogen are prone to be degraded by oxidation. These oxidation reactions would lead to a gradual denitrogenation and a transformation from the condensed pyridinic rings (center-N) to peri-located (top or valley-N) pyridone and pyridine.

The detailed observation of the nitrogen distribution given by N1s XPS and N1s XANES for the different modes of activation gives a more contrasted picture of the transformation of nitrogen functionalities during Nomex fiber activation. For instance, the relative abundance of substitutional nitrogen in condensed polyaromatic systems noticeably increases during NP75 carbonization from 873 to $1073 \mathrm{~K}$ (Fig. 5a), but decreases with increasing impregnation ratio at the same final carbonization temperature. These two opposite trends could be due to a double process of aromatization and " 'auto-activation', producing an oxidative attack of nitrogen, corresponding to the important release of gases above $873 \mathrm{~K}$ (Fig. 1), with an increase of the P2 nitrogen type - correlated with a systematic increase of the $u / n$ ratio after activation. These reactions would occur more sequentially during physical activation, which involves a carbonization stage followed by an activation one with a co-occurrence of isothermal heating (aromatization) and thermal-oxidation. At equivalent burn-off, denitrogenation rate is lower during $\mathrm{CO}_{2}$ activation than during steam activation (Fig. 4b), as the latter produces both hydrogen and hydroxyl radical attack of the nitrogen-containing polyaromatic systems. In this case, the P3 increase is not simply due to pyridine condensation but to pyridinic nitrogen protonation by bridge formation with adjacent or nearby located hydroxyl oxygen groups as evidenced by water TPD. As seen by elemental analysis (Table 2) and TPD (Table 4 and Fig. 1), $\mathrm{CO}_{2}$ activation following $\mathrm{H}_{3} \mathrm{PO}_{4}$ impregnation and carbonization lead to a stronger denitrogenation than the one observed during unimpregnated Nomex char $(\mathrm{N})$ activation. However, in this case, as shown in Fig. 5b, the apparent surface oxidation of nitrogen, measured by the relative change of
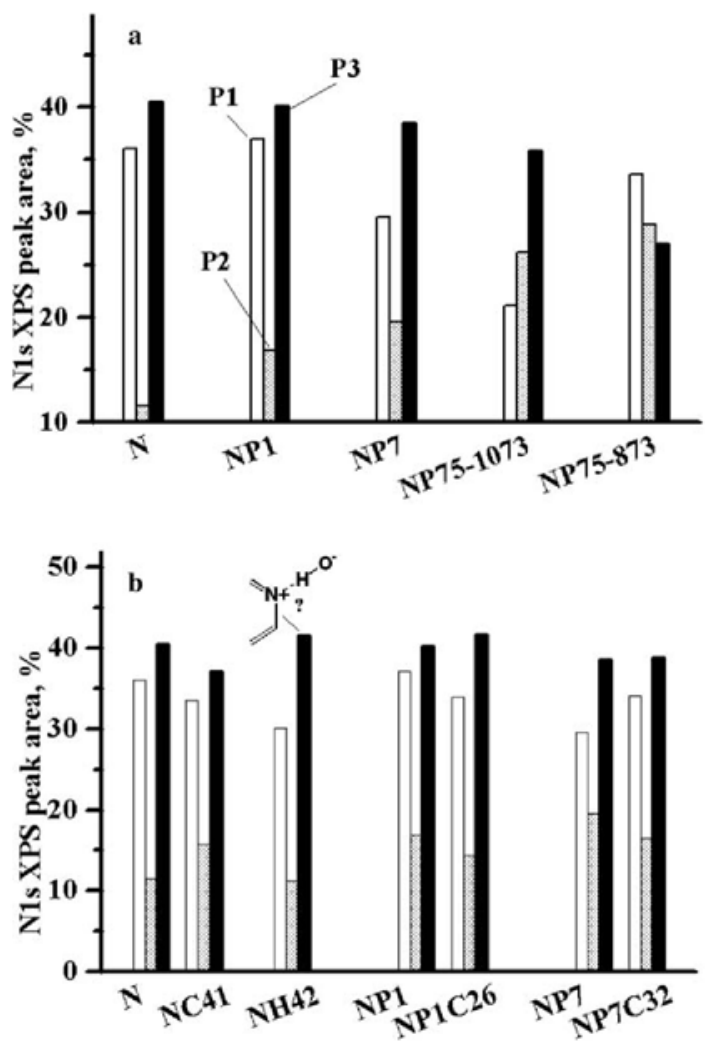

Fig. 5. Effect of the activation mode on the distribution of the N1s XPS and $\mathrm{n}_{*}$ XAS components in NACFs: (a) $\mathrm{H}_{3} \mathrm{PO}_{4}$ impregnation; (b) physical activation alone or after $\mathrm{H}_{3} \mathrm{PO}_{4}$ impregnation.

lower than the one reached with char $\mathrm{N}$ activation - in spite of an equivalent development of the porosity measured by the wide micropore volumes (difference between the micropore volumes obtained by $\mathrm{N}_{2}$ and $\mathrm{CO}_{2}$ adsorption). In other words, increased denitrogenation during $\mathrm{CO}_{2}$ activation, after Nomex impregnation with phosphoric acid and subsequent carbonization, would be due to the abundant oxygen substituents on $\mathrm{N}$ cycles introduced during $\mathrm{H}_{3} \mathrm{PO}_{4}$ activation.

\subsection{Surface vs. bulk}

Correlation plots between XPS atomic N/C or O/C ratios and elemental analysis atomic $\mathrm{N} / \mathrm{C}$ ratios for NACFs are shown in Fig. 6a and b. The two correlation lines fall below the surface-bulk parity (indicated by the dashed line). The difference in $\mathrm{N}$ and $\mathrm{O}$ contents between the surface and the bulk of the carbon material could be attributed to an inaccurate calibration using inappropriate XPS sensitivity factors for the particular carbon samples under study. Though nitrogen and oxygen are expressed with respect to carbon, the oxidation propensity of the carbon surface exposed to atmospheric air could also explain the compositional deviation due to modification of the secondary electron travel through the oxidized surface layers of the carbon sample. As suggested by previous work [46], surface nitrogen depletion as seen by XPS could 

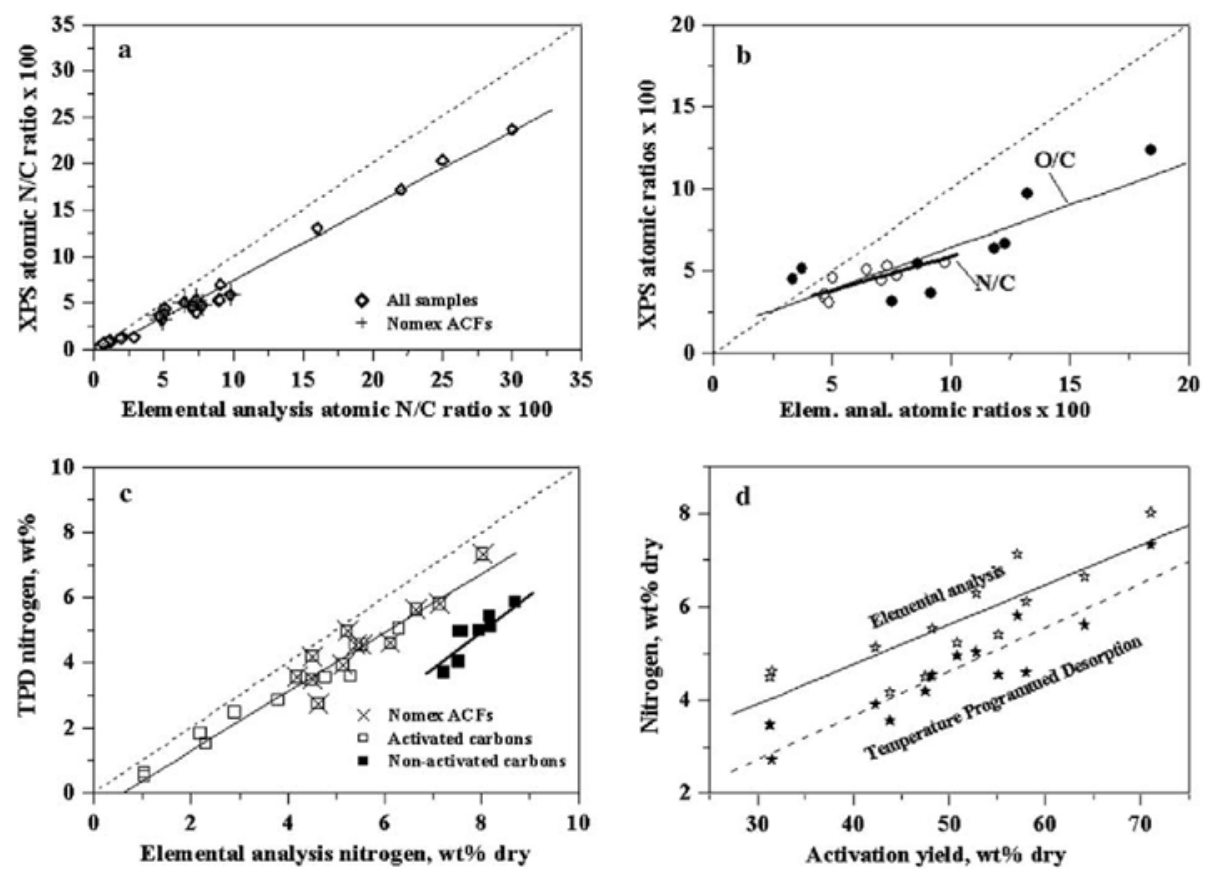

Fig. 6. Correlations between surface and bulk analyses for NACFs and reference samples [8,27,41,42,51]: (a) surface vs. bulk N/C ratio; (b) surface N/C and $\mathrm{O} / \mathrm{C}$ ratios vs. elemental ratios; (c) TPD nitrogen yield vs. elemental nitrogen content; (d) nitrogen content or TPD nitrogen yield vs. activation yield.

be accounted for by a pure thermal preferential surface denitrogenation either of previously activated carbon material or during the activation process itself, which involves both purely thermal and thermo-oxidative reactions. This is suggested by Fig. 6c, where nitrogen appears to be more easily thermally desorbed from activated carbons with a larger surface area than from massic/nonactivated ones.

Assuming that differential surface denitrogenation is the most important factor contributing to the deviation of the $\mathrm{N}$ correlation line below the surface-bulk parity, the smallest deviation for the samples containing the lowest nitrogen content could be explained by a more intense denitrogenation process that would have minimized the difference between surface and bulk. On the contrary, a better preservation of the initial nitrogen contained in the precursor polyaramid fibers would underline the nitrogen surface depletion observed by XPS. In this respect, the preferential surface denitrogenation and its specific effects on the nitrogen distribution (Fig. 5) are more obvious for the $\mathrm{H}_{3} \mathrm{PO}_{4}$ activated carbons, where the difference between surface and bulk N/C is linearly correlated with the carbonization/activation yield. Hence, the correlation between the nitrogen content and the carbonization/activation yield (Fig. 6d) illustrates the surface denitrogenation of the Nomex fibers by the activating agents. Freeman et al. [47] found that Nomex based chars contain much less nitrogen than comparable Kevlar-derived chars (as confirmed by Cuesta et al. [48]), possibly due to the accessible and more uniform nature of the char structure, thus allowing reaction of nitrogen groups with carbon dioxide or steam to occur more freely. Several authors have reported that, in comparison with $\mathrm{CO}_{2}$, steam specifically reacts with nitrogen groups, thereby reducing more the $\mathrm{N} / \mathrm{C}$ ratio with increasing bum-off during physical activation of polyacrylonitrile chars $[49,50]$.

\section{Conclusions}

In the framework of a work on the chemistry of porosity development during carbon activation and of the resulting carbon surface, we have conducted a combined study by TPD, XPS and XANES on the local bonding environment around nitrogen in Nomex-based activated carbon fibers, as a function of the activation mode and of the burn-off degree, in order to understand the changes in nitrogen content and nitrogen functionality distribution during carbonization/activation. The nitrogen bonding structure was shown to vary with the preparation treatments. Comparison of the data showed that in all cases thermal reactions occur preferentially at the sample surface and involve both aromatization reactions forming more condensed nitrogen species and degradative reactions of condensed pyridinic nitrogen with further oxidation of nitrogen atoms located at the edge of polyaromatic systems. These reactions occur more sequentially during physical activation, which involved a carbonization stage followed by an activation stage with a co-occurrence of isothermal heating (aromatization) and thermal-oxidation. At equivalent burn-off, the extent of nitrogen removal was lower during $\mathrm{CO}_{2}$ activation than during steam activation, which produced an attack of the nitrogen-containing polyaromatic systems with hydroxyl oxygen group formation by $\mathrm{OH}^{\prime}$ or $\mathrm{H}^{\prime}$ radical reaction with the carbon surface. Impregnation with 
$\mathrm{H}_{3} \mathrm{PO}_{4}$ led to a higher carbonization/activation yield and a greater preservation of $\mathrm{N}$-containing groups due to early dehydration and crosslinking reactions forming the micropore network. In this activation mode, the nitrogen group distribution is also controlled by two simultaneous reactions: strong aromatization, and surface oxidative denitrogenation due a secondary activation triggered by gases released at high temperature (more important at higher impregnation rate). Abundant oxygen substituents introduced during $\mathrm{H}_{3} \mathrm{PO}_{4}$ activation on the $\mathrm{N}$-containing cycles enhanced a stronger thermal char denitrogenation during subsequent $\mathrm{CO}_{2}$ activation in the combined $\mathrm{H}_{3} \mathrm{PO}_{4}-\mathrm{CO}_{2}$ activation mode. This enhanced denitrogenation rate is in agreement with previously observed increased reactivity with $\mathrm{CO}_{2}$ of phosphoric acid impregnated Nomex chars with respect to the nonimpregnated one [52].

The results of the present study show that the use of various techniques in combination provides a powerful tool for assessing the nitrogen local bonding structure. Temperature programmed desorption gave a survey of nitrogen group abundance, distribution and chemical context in NACFs. XPS provided the most direct way to detect and quantify the proportions of nitrogen species. Three main components were used to fit the spectrum envelope, namely pyridinic nitrogen, condensed pyridinic nitrogen and an unknown intermediate component. The $\mathrm{n} *$ resonance spectra recorded by $\mathrm{N}$ K-edge XANES in total electron yield (TEY) detection were correlated with N1s XPS spectra in order to improve the structural interpretation of the intermediate component (N2). XANES showed that N2 would not host any pyrrolic nitrogen. On the basis of reactional behaviour and correlations, we assumed that N2, which could contain a small amount of nitrile groups - as revealed by $\mathrm{N}$ K-edge XANES, should be rather related to a pyridinic cycle bearing oxygen substituents or intracyclic oxygen atoms making the cycle more prone to be open by thermal cracking. This opening would occur during TPD by releasing both $\mathrm{HCN}$ and $\mathrm{N}_{2}$ at lower temperature, instead of pure $\mathrm{N}_{2}$ formed by surface or gas phase radical recombination as a result of hydrogen starvation at higher temperature. The actual bonding configuration yielding this intermediate spectrum feature, occurring between those of pyridinic nitrogen and substitutional nitrogen in condensed polyaromatic systems, remains an opened question, to which further efforts are being devoted.

\section{Acknowledgements}

Financial support from the Spanish MCYT (project BQU2001-2936-C02-02) is gratefully acknowledged. The authors thank their colleagues Javier Ferna'ndez, Blanca Llorente and Celina Blanco for providing the starting Nomex® samples. XPS measurements were performed in collaboration with M. Chehimi and C. Bilem from ITODYS, University of Paris VII (France). This paper was substan tially improved by constructive reviews and suggestions from two anonymous reviewers.

\section{References}

[1] Freeman JJ, Gimblett FGR, Hayes RA, Amin ZM, Sing KSW. Adsorptive properties of activated carbons prepared from Kevlar®. In: Rodrı'guez-Reinoso F, Rouquerol J, Sing KSW, Unger KK, editors. Characterization of porous solids II. Amsterdam: Elsevier; 1991.

[2] Villar-Rodil S, Suarez-Garcıa F, Paredes JI, Martı́nez-Alonso A, Tascón JMD. Activated carbon materials of uniform porosity from polyaramid fibers. Chem Mater 2005;17:5893-908.

[3] Amenomiya Y, Pleizier G. Chemisorption of gases on a promoted iron catalyst I. Hydrogen, nitrogen, carbon monoxide and carbon dioxide. J Catal 1973;28(3):442-54.

[4] Amenomiya Y, Pleizier G. Chemisorption of gases on a promoted iron catalyst II. Exchange between deuterium and preadsorbed ammonia. J Catal 1973;29(2):319-27.

[5] Kawai T, Jiang KM, Ishikawa T. FT-IR and TPD Studies of adsorbed pyridine on Re207/A1203 catalysts. J Catal 1996;159(2): 288-95.

[6] Niwa M, Nishikawa S, Katada N. IRMS-TPD of ammonia for characterization of acid site in o-zeolite. Microp Mesop Mater 2005; 82(1-2):105-12.

[7] Boudou JP, Chehimi M, Broniek E, Siemieniewska T, Bimer J. Adsorption of $\mathrm{H}_{2} \mathrm{~S}$ or $\mathrm{SO}_{2}$ on an activated carbon cloth modified by ammonia treatment. Carbon 2003;41(10):1999-2007.

[8] Xiao B, Boudou JP, Thomas KM. Reactions of nitrogen and oxygen surface groups in nanoporous carbons under inert and reducing atmospheres. Langmuir 2005;21(8):3400-9.

[9] Zhu Q, Money SL, Russell AE, Thomas KM. Determination of the fate of nitrogen functionality in carbonaceous materials during pyrolysis and combustion using X-ray absorption near edge structure spectroscopy. Langmuir 1997;13(7):2149-57.

[10] Ripalda JM, Román E, Diaz N, Gala'n L, Montero I, Comelli G, et al. Correlation of X-ray absorption and X-ray photoemission spectroscopies in amorphous carbon nitride. Phys Rev B 1999;60(6): R3705-8.

[11] Quiros C, Gomez-Garcia J, Palomares CJ, Soriano L, Elizalde E, Sanz JM. Correlation between N1s core level X-ray photoelectron and X-ray absorption spectra of amorphous carbon nitride films. Appl Phys Lett 2000;77(6):803-5.

[12] Hellgren N, Guo J, Luo Y, Sathe C, Agui A, Kashtanov S, et al. Electronic structure of carbon nitride thin films studied by $\mathrm{X}$-ray spectroscopy techniques. Thin Solid Films 2005;471(1-2):19-34.

[13] Sua'rez-García F, Martı́nez-Alonso A, Tascón JMD. Nomex polyaramid as a precursor for activated carbon fibres by phosphoric acid activation. Temperature and time effects. Micropor Mesopor Mater 2004;75(1-2):73-80.

[14] Kirschstein J. Pyrolyse von Steinkohlen und kohlestrukturrelevanten Polymeren. Essen, Germany, GHS-Essen University, 1989, PhD Thesis.

[15] Trick KA, Saliba TE. Mechanisms of the pyrolysis of phenolic resin in a carbon/phenolic composite. Carbon 1995;33(11):1509-15.

[16] Calo JM, Cazorla-Amoros D, Linares-Solano A, Roman-Martinez MC, Salinas-Matinez De Lecea C. The effects of hydrogen on thermal desorption of oxygen surface complexes. Carbon 1997;35(4):543-54.

[17]Kuo HH, Lin JHC, Ju CP. Effect of carbonization rate on the properties of a PAN/phenolic-based carbon/carbon composite. Carbon 2005;43(2):229-39.

[18]Wang H, Dlugogorski BZ, Kennedy EM. Thermal decomposition of solid oxygenated complexes formed by coal oxidation at low temperatures. Fuel 2002;81(15):1913-23.

[19] Papirer E, Dentzer J, Li S, Donner JB. Surface groups on nitric acid oxidised carbon-black samples determined by chemical and thermodesorption analyses. Carbon 1991;29(1):69-72. 
[20] Otake Y, Jenkins RB. Characterization of oxygen-containing surface complexes created oil a microporous carbon by air and nitric acid treatment. Carbon 1993;31(1):109-21.

[21] Benedetti MF, Lablanchy P, Boudou JP, Martinez-Alonso A, Tascon JMD. Analysis of surface oxides generated by oxygen plasma treatment of carbons. Am Chem Soc, Div Fuel Chem Preprints 1998;43(4):829-32.

[22] Figueiredo JL, Pereira MFR, Freitas MMA, O rfa o JJM. Modification of the surface chemistry of activated carbons. Carbon 1999;37(9): 1379-89.

[23] Szymaski GS, Karpiski Z, Biniak S, Witkowskic A. The effect of the gradual thermal decomposition of surface oxygen species on the chemical and catalytic properties of oxidized activated carbon. Carbon 2002;40(14):2627-39.

[24] Strelko VV, Kartel NT, Dukhno IN, Kuts VS, Clarkson RB, Odintsov BM. Mechanism of reductive oxygen adsorption on active carbons with various surface chemistry. Surf Sci 2004;548(1-3): 281-90.

[25]Zhang LH, Calo JM. Thermal desorption methods for porosity characterization of carbons and chars. Colloid Surf A 2001;187188:207-18.

[26] Lahaye J, Nanse G, Fioux Ph, Bagreev A, Broshnik A, Strelko V. Chemical transformation during the carbonisation in air and the pyrolysis under argon of a vinylpyridine-divinylbenzene copolymer by X-ray photoelectron spectroscopy. Appl Surf Sci 1999;147(1-4): 153-74.

[27]Pels JR, Kapteijn F, Moulijn JA, Zhu Q, Thomas KM. Evolution of nitrogen functionalities in carbonaceous materials during pyrolysis. Carbon 1995;33(11):1641-53.

[28] Sa'nchez-Lo'pez JC, Donnet C, Lefebvre F, Fernando-Ramos C, Ferna'ndez A. Bonding structure in amorphous carbon nitride: NMR, EELS, XANES and XPS study. J Appl Phys 2001;90(2):675-81.

[29] Casanovas J, Ricart JM, Rubio J, Illas F, Jime'nez-Mateos JM. Origin of the large N1s binding energy in X-ray photoelectron spectra of calcined carbonaceous materials. J Am Chem Soc 1996;118(34): 8071-6.

[30] Neidhardt J, Hultman L, Czigany ZS. Correlated high resolution transmission electron microscopy and $\mathrm{X}$-ray photoelectron spectroscopy studies of structured $\mathrm{CN}_{\mathrm{x}}(0<\mathrm{x}<0.25)$ thin solid films. Carbon 2004;42(12-13):2729-34.

[31] Kelemen SR, Gorbaty ML, Kwiatek PJ. Quantification of nitrogen forms in Argonne Premium Coals. Energy Fuels 1994;8(4):896-906.

[32] Zeng XM, Chan CM, Weng LT, Li L. Surface characterization and quantitative study of poly(4-vinyl phenol) and poly(4-vinyl pyridine) blends by XPS and ToF-SIMS. Polymer 2000;41(23):8321-9.

[33] Gammon WJ, Hoatson GL, Holloway BC, Vold RL, Reilly AC. Bonding in hard and elastic amorphous carbon nitride films investigated using ${ }^{15} \mathrm{~N},{ }^{13} \mathrm{C}$, and ${ }^{1} \mathrm{H}$ NMR spectroscopy. Phys Rev 2003;B 68:195401-1-1-8.

[34] Liu S, Chan CM, Weng LT, Jiang M. Surface quantitative characterization of poly(styrene-co-4-vinyl phenol)/poly(styrene-co-4vinyl pyridine) blends with controlled hydrogen bonding interactions. Polymer 2004;45(14):4945-51.

[35] Schmiers H, Friebel J, Streubel P, Hesse R, Ko psel R. Change of chemical bonding of nitrogen of polymeric N-heterocyclic compounds during pyrolysis. Carbon 1999;37(12):1965-78.
[37] Axworthy AE, Dayan VH, Martin BG. Reactions of fuel-nitrogen compounds under conditions of inert pyrolysis. Fuel 1978;57(1): 29-35.

[38]Bruisma GSL, Geertsma RS, Bank P, Moulijn JA. Gas phase pyrolysis of coal-related aromatic compounds in a coiled tube flow reactor. Fuel 1988;67(3):327-33.

[39] Bruisma GSL, Tromp PJJ, de Sauvage Nolting HJJ, Moulijn JA. Gas phase pyrolysis of coal-related aromatic compounds in a coiled tube flow reactor. 2. Heterocyclic compounds, their benzo and dibenzo derivatives. Fuel 1988;67(3):334-40.

[40]Li C-Z, Buckley AN, Nelson PF. Effects of temperature and molecular mass on the nitrogen functionality of tars produced under high heating rate conditions. Fuel 1998;77(3):157-64.

[41] Bimer J, Salbut PD, Berlozecki S, Boudou JP, Broniek E, Siemieniewska T. Modified active carbons from precursors enriched with nitrogen functions: sulfur removal capabilities. Fuel 1998;77(6): 519-25.

[42]Cagniant D, Gruber R, Boudou JP, Bilem C, Bimer J, Salbut D. Structural characterization of nitrogen-enriched coals. Energy Fuels 1998;12(4):672-81.

[43]Burg P, Fydrych P, Cagniant D, Nanse G, Bimer J, Jankowska A. The characterization of nitrogen-enriched activated carbons by IR, XPS and LSER methods. Carbon 2002;40(9):1521-31.

[44] Cagniant D, Magri P, Gruber R, Berlozecki S, Salbut PD, Bimer J, et al. Ammoxidation of cellulose - a structural study. J Anal Appl Pyrol 2002;65(1):1-23.

[45] Raymundo-Pin ero E, Cazorla-Amoro’s D, Linares-Solano A, Find J, Wild U, Schlo"gl R. Structural characterization of Ncontaining activated carbon fibers prepared from a low softening point petroleum pitch and a melamine resin. Carbon 2002;40(4):597-608.

[46] Kapteijn F, Moulijn JA, Matzner S, Boehm HP. The development of nitrogen functionality in model chars during gasification in $\mathrm{CO}_{2}$ and O. Carbon 1999;37(7):1143-50.

[47] Mittal J, Konno H, Inagaki M, Bahl OP. Denitrogenation behavior and tensile strength increase during carbonization of stabilized PAN fibers. Carbon 1998;36(9):1327-30.

[48] Freeman JJ, Tomlinson JB, Sing KSW, Theocharis CR. Adsorption of nitrogen and water vapour by activated Nomex chars. Carbon 1995;33(6):795-9.

[49] Cuesta A, Martınez-Alonso A, Tascon JMD, Bradley RH. Chemical transformation resulting from pyrolysis and $\mathrm{CO}_{2}$ activation of Kevlar flocks. Carbon 1997;35(7):967-76.

[50]Wang PH, Yue ZR, Liu J. Conversion of polyacrylonitrile fibers to activated carbon fibers: effect of activation. J Appl Polym Sci 1996; 60(7):923-9.

[51]Carrott PJM, Nabais JMV, Ribeiro Carrott MML, Pajares JA. Preparation of activated carbon fibres from acrylic textile fibres. Carbon 2001;39(10):1543-55.

[52] Raymundo-Pinero E, Cazorla-Amoros D, Linares-Solano A Find J, Wild U, Schlogl R. Structural characterization of Ncontaining activated carbon fibers prepared from a low softening point petroleum pitch and a melamine resin. Carbon 2002;40(4):597-608.

[53] Suarez-Garcia F, Martmez-Alonso A, Tascon JMD. Beneficial effects of phosphoric acid as an additive in the preparation of activated carbon fibers from Nomex aramid fibers by physical activation. Fuel Proc Technol 2002;77-78:237-44. 